\title{
A respiratory gas exchange catheter: In vitro and in vivo tests in large animals
}

Brack G. Hattler, MD, PhD

Laura W. Lund, PhD

Joseph Golob, BS

Heide Russian, BS

Michael F. Lann, BS

Thomas L. Merrill, PhD

Brian Frankowski, AD

William J. Federspiel, PhD
From the Department of Surgery, University of Pittsburgh School of Medicine, Pittsburgh, Pa.

Read at the Eighty-first Annual Meeting of The American Association for Thoracic Surgery, San Diego, Calif, May 6-9, 2001.

Received for publication Aug 20, 2001; revisions requested Nov 19, 2001; revisions received Nov 30, 2001; accepted for publication Dec 20, 2001.

Address for reprints: Brack G. Hattler, MD, PhD, Department of Surgery, University of Pittsburgh School of Medicine, Pittsburgh, PA 15213 (E-mail: hattlerbg@msx.upmc.edu)

J Thorac Cardiovasc Surg 2002;124: 520-30

Copyright (C) 2002 by The American Association for Thoracic Surgery

$0022-5223 / 2002 \$ 35.00+0 \quad \mathbf{1 2 / 6 / 1 2 3 8 1 1}$

doi: $10.1067 / \mathrm{mtc} .2002 .123811$
Objectives: Acute respiratory failure is associated with a mortality of $40 \%$ to $50 \%$, despite advanced ventilator support and extracorporeal membrane oxygenation. A respiratory gas exchange catheter (the Hattler Catheter) has been developed as an oxygenator and carbon dioxide removal device for placement in the vena cava and right atrium in the treatment of acute respiratory failure to improve survival.

Methods: Differing from a previously clinically tested intravenous gas exchange device (ie, IVOX), the Hattler Catheter incorporates a small, pulsating balloon surrounded by hollow fibers. The pulsating balloon redirects blood toward the fibers, enhances red cell contact with the membrane, and significantly improves gas exchange so that smaller catheter devices are still efficient on insertion and can be inserted through the jugular or femoral vein. Devices were tested in mock circulatory loops and in short-term ( 8 hours) and long-term (4 days) experiments in calves to study the effect of various sized balloons and the anatomic location of the device in the venous system as a function of hemodynamics and gas exchange.

Results: In vitro performance in water demonstrates an oxygen delivery $\left(\mathrm{VO}_{2}\right)$ of $140 \pm 8.9 \mathrm{~mL} \cdot \mathrm{min}^{-1} \cdot \mathrm{m}^{-2}$ and a carbon dioxide removal $\left(\mathrm{VCO}_{2}\right)$ of $240 \pm 6.1 \mathrm{~mL}$ $\cdot \min ^{-1} \cdot \mathrm{m}^{-2}$. Acute in vivo experiments demonstrate a maximum carbon dioxide consumption of $378 \pm 11.2 \mathrm{~mL} \cdot \mathrm{min}^{-1} \cdot \mathrm{m}^{-2}$. Devices positioned in the right atrium had an average carbon dioxide exchange of $305 \mathrm{~mL} \cdot \mathrm{min}^{-1} \cdot \mathrm{m}^{-2}$, whereas in the inferior vena cava position carbon dioxide exchange was $255 \mathrm{~mL} \cdot \mathrm{min}^{-1}$. $\mathrm{m}^{-2}$. Devices have been tested long term in calves, with gas exchange rates maintained over this time interval (carbon dioxide consumption, $265 \pm 35 \mathrm{~mL}$. $\min ^{-1} \cdot \mathrm{m}^{-2}$ ). Plasma-free hemoglobin levels at the end of 4 days have been $4.8 \pm$ $3.2 \mathrm{mg} / \mathrm{dL}$. Hemodynamic measurements, including a decrease in cardiac outputs and increased mean pressure decreases across the device become significant only with the larger balloon $(40-\mathrm{mL})$ devices $(P<.05,40-\mathrm{mL}$ vs $13-\mathrm{mL}$ devices). Autopsies show no end-organ damage. The device linearly increases its carbon dioxide output with progressive hypercapnea, predicting its ability to meet tidal volume reduction in the therapy of respiratory failure.

Conclusions: Progress has been made toward developing an intravenous gas exchange catheter to provide temporary pulmonary support for patients in acute respiratory failure. 


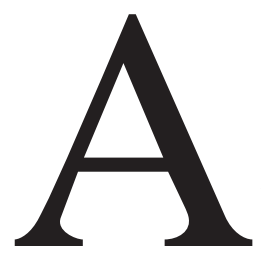

cute respiratory failure from a variety of causes is one of the main concerns in the care of patients in intensive care units. One form of severe acute respiratory failure, the acute respiratory distress syndrome (ARDS), although first described by Ashbaugh and colleagues ${ }^{1}$ in 1967 , continues to exhibit a mortality in adults of approximately $40 \%$ to $50 \%$, despite a better understanding of the pathophysiology responsible for this condition. ${ }^{2,3}$ For the patient with acute respiratory failure, maintaining gas exchange at a level consistent with survival is associated frequently with progressively increasing levels of ventilator support. A review of our recent experience with 1839 patients who were placed on ventilators because of a primary respiratory problem has indicated, not surprisingly, that mortality after intubation, oxygen delivery, and use of the respirator increases the longer a patient is ventilated. ${ }^{4}$ For the 799 patients within this group requiring ventilation for greater than 96 hours, a mortality of $37 \%$ was noted. These findings underscore the need for improved approaches to this patient population and constitute the basis for the continuing interest in the development of better ventilator strategies, new drug therapies, and artificial lung devices for the treatment of acute lung failure and the management of patients on ventilators. ${ }^{5-11}$

We have concentrated our efforts in one of these areas as it relates to the development of an intravenous hollow fiber membrane respiratory assist catheter, the Hattler Catheter (HC). ${ }^{11-21 *}$ Differing from a previous intravenous gas exchange device tested clinically (the IVOX), it incorporates a balloon surrounded by microporous hollow fiber membranes. ${ }^{22-24}$ The pulsating balloon redirects blood toward the fibers, enhances red cell contact with the membranes, and significantly improves oxygen and carbon dioxide exchange. ${ }^{4,12,25}$ The underlying bioengineering concepts that are fundamental to gas exchange in blood have been instrumental in guiding research in this new field and have formed the basis for our continuing and most recent efforts in this area. Our clinical goal has been to provide $50 \%$ of basal oxygen and carbon dioxide exchange, as determined by calculated gas exchange requirements for an adult patient with various levels of pulmonary damage and residual functional lung (Figure 1). The ability to achieve a life-sustaining arterial oxygen saturation of greater than $90 \%\left(\mathrm{Po}_{2}\right.$ of 60 $\mathrm{mm} \mathrm{Hg}$ ) with only $30 \%$ of the lung still functional would require that a respiratory assist catheter add an additional 100 to $125 \mathrm{~mL} / \mathrm{min}$ oxygen to the patient's bloodstream (Figure 1). This represents approximately $50 \%$ of basal oxygen requirements.

This article describes the results of complementary in

*Also reported in previous publications as the intravenous membrane oxygenator. The catheter-based device, however, exchanges both oxygen and carbon dioxide. Simply describing it as a membrane oxygenator is not accurate. The $\mathrm{HC}$ is intended for respiratory support in cases of acute respiratory failure. vitro and bovine in vivo experiments conducted to compare the gas exchange performance and hemodynamic effects of devices having different balloon sizes but the same fiber length and surface area. The in vitro tests were performed to characterize and compare the gas exchange performance of devices with design-parameter variations, such as balloon size, under carefully controlled conditions. The acute in vivo tests were then performed to evaluate whether these performance characteristics were sensitive to anatomic and physiologic variations in situ and to evaluate their hemodynamic effects. Finally, chronic 4-day in vivo trials were conducted with the device determined most optimal on the basis of the in vitro and acute in vivo studies to evaluate device performance and hemodynamic effects over time.

\section{Materials and Methods}

\section{Respiratory Assist Catheters}

The HC devices used in these experiments were sized on the basis of the diameters and lengths of the inferior vena cava (IVC) and superior vena cava (SVC) of a calf, which have more constrained dimensions than those of an adult human. Each device had a fiber bundle surface area of $0.17 \mathrm{~m}^{2}$ comprised of 600 polypropylene hollow fiber membranes (x30-240; Celgard, Charlotte, NC) with inner and outer diameters of $240 \mu \mathrm{m}$ and $300 \mu \mathrm{m}$, respectively. The proximal and distal manifolds in which the hollow fibers were potted had a diameter of $9 \mathrm{~mm}$, which dictates the minimal insertional size of the device. A schematic of the catheter is shown in Figure 2. Hollow fiber membrane mats surround the central balloon in concentric layers. The 3 ports to the exit manifold supply oxygen, a vacuum, and a helium port connected to an external console that inflates and deflates the balloon at up to 300 beats/min. Devices having 3 balloon sizes were tested: a $13-\mathrm{mL}$ balloon with a diameter of $9.5 \mathrm{~mm}$, a $25-\mathrm{mL}$ balloon with a diameter of $12.5 \mathrm{~mm}$, and a $40-\mathrm{mL}$ balloon with a diameter of 15 $\mathrm{mm}$.

\section{In Vitro Characterization}

Before in vivo testing, each device was characterized in a mock venous circulatory test circuit with water at $37^{\circ} \mathrm{C}$. Water is used routinely in testing gas exchange parameters of artificial lung devices because it is easier to handle on a daily basis than is blood. Water data, however, are accurately converted to data obtained with blood by multiplying water results by 2 to 3 times depending on the conditions of the experiment, as detailed in the work of Vaslef and associates ${ }^{26}$ and confirmed by our laboratory. ${ }^{27}$ The test circuit consisted of an acrylic test section with a 1-inch $(25 \mathrm{~mm})$ inner diameter, 2 compliance bags on both ends of the test section, a Biomedicus centrifugal pump, a reservoir container, a circulating temperature bath, and a standard extracorporeal oxygenator used to establish desired test section inlet oxygen and carbon dioxide conditions. A 3/4-inch $(19 \mathrm{~mm})$ inner diameter test section was also interchanged with the 1 -inch $(25 \mathrm{~mm})$ piece to evaluate the effects of vessel diameter on gas exchange and water side pressure decreases across the device. A rotameter was used to measure water flow, and a thermocouple thermometer was used to measure water temperature immediately after the test section. All reported in vitro gas exchange measurements were made at a water flow 


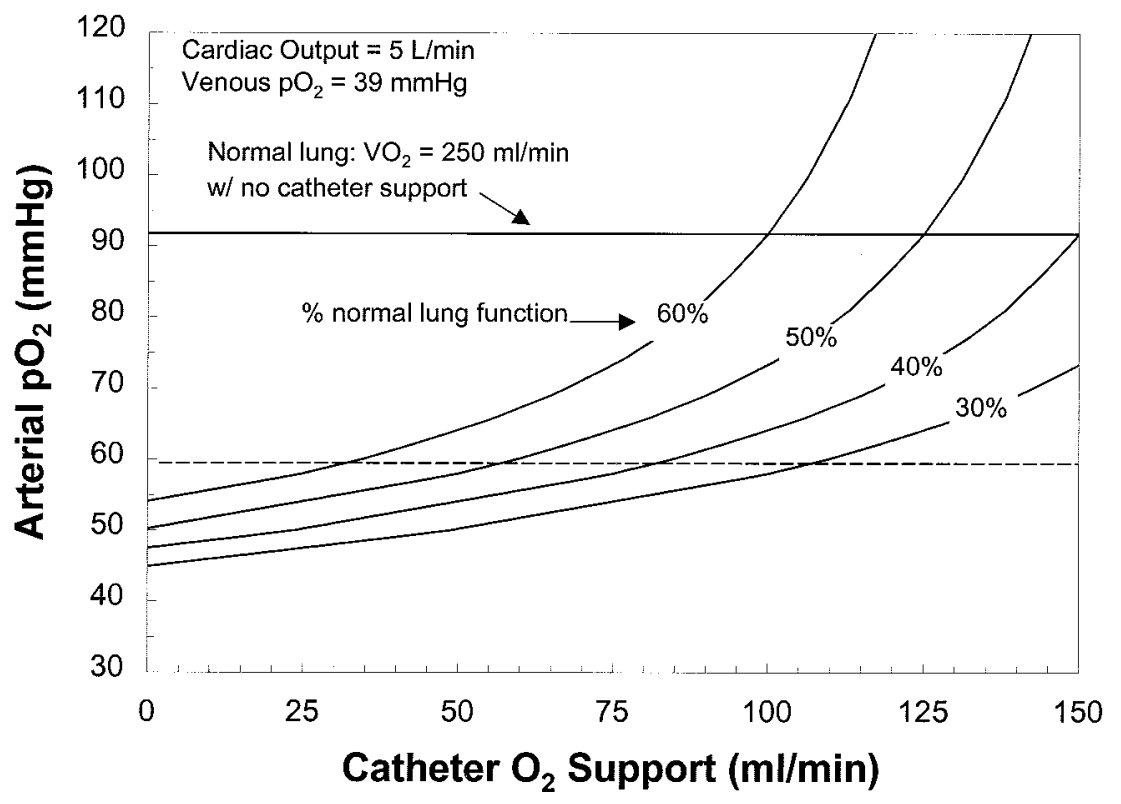

Figure 1. The amount of oxygen that a respiratory assist catheter positioned in the venous system would have to add to an adult patient with a normal hematocrit level, cardiac output of $5 \mathrm{~L} / \mathrm{min}$, and venous $\mathrm{Po}_{2}$ of $39 \mathrm{~mm} \mathrm{Hg}$ to achieve an arterial $\mathrm{PO}_{2}$ of $60 \mathrm{~mm} \mathrm{Hg}$, as determined by the amount of residual lung still functional.

rate of $3 \mathrm{~L} / \mathrm{min}$ and inlet gas tensions of $50 \mathrm{~mm} \mathrm{Hg}$ for carbon dioxide and $30 \mathrm{~mm} \mathrm{Hg}$ for oxygen. Pure oxygen gas was pulled through the fibers under vacuum conditions at a flow rate of 3 $\mathrm{L} / \mathrm{min}$, which corresponded to the minimum rate at which carbon dioxide removal was not compromised but which provided a minimal gas side pressure decrease so as to maintain a large driving gradient for oxygen exchange. ${ }^{28}$ Balloon pulsation was driven with a specially designed pneumatic drive system consisting of positive pressure and a vacuum reservoir connected through alternating solenoid valves to a safety chamber enclosing an external balloon. The inside of this balloon was connected by a tube to the device balloon pathway so that pressurization of the external balloon resulted in inflation of the device balloon and vice versa. Gas exchange measurements for each device were measured over a range of balloon pulsation rates spanning 0 beats/min to the maximum rate at which the given balloon size could be fully inflated and deflated, as determined with a plethysmograph. Carbon dioxide exchange was calculated from measurements of the sweep gas mass flow rate and the percentage of carbon dioxide exiting the fiber bundle (measured with a mass spectrometer), whereas oxygen exchange was calculated from measurements of the water flow and the difference in partial pressure of oxygen in the water flow before and after device insertion, as measured with a blood gas analyzer (radiometer).

\section{Acute In Vivo Characterization}

The in vivo performance of the HC with different balloon volumes was studied in 7 calves weighing $93.9 \pm 9.9 \mathrm{~kg}$. A detailed description of the methods used for animal preparation, maintenance, and monitoring for insertion and characterization of the $\mathrm{HC}$ device can be found in a previous publication. ${ }^{14}$ In short, the calves were anesthetized, intubated, and placed on a volume-controlled ventilator. Before device insertion, a 7F Swan-Ganz thermodilution catheter (Edwards Lifesciences, Irvine, Calif) was inserted through the left internal jugular vein for measurement of cardiac output, central venous pressure, pulmonary artery pressure, and blood gases after device insertion. Additionally, a pressure-monitoring catheter was inserted into the common iliac vein through the left femoral vein for measurement of blood pressure and gas tensions before device insertion, as well as for continuous delivery of heparin. Finally, an 18-gauge arterial catheter was inserted into the right carotid artery for measurement of arterial blood pressures and gas tensions.

Blood gases, pressures, and cardiac outputs were measured every half hour during the course of the experiment in addition to special measurements taken immediately before and after device insertion and after changes in balloon pulsation rate. Because these devices did not yet have a heparin molecule attached to the microporous hollow fiber membrane surface, animals were heparinized with an initial bolus ( $400 \mathrm{U} / \mathrm{kg}$ ) immediately before device insertion and through a continuous drip $\left(0.5-1.0 \mathrm{mg} \cdot \mathrm{kg}^{-1} \cdot \mathrm{h}^{-1}\right)$ initiated thereafter. Activated clotting time was measured every half hour, with a target level of greater than 450 seconds. Levels of plasma-free hemoglobin were measured after surgical preparation but before device insertion and throughout the experiment.

The HC device was preloaded into a removable Teflon sheath that minimized the insertion size of the fiber bundle and the friction with the vessel wall during insertion. Each device was then inserted into the vena cava through the left internal jugular vein. The device was positioned such that the distal manifold was in the IVC approximately at the diaphragm, with the fiber bundle spanning the right atrium and the proximal manifold in the SVC. After 
each device was inserted and positioned, balloon pulsation was immediately initiated at 120 beats/min, followed by initiation of sweep gas flow (100\% oxygen) at $3 \mathrm{~L} / \mathrm{min}$. Gas exchange characterization began after an initial stabilization period, during which the ventilator was used to adjust the venous carbon dioxide tension to within $10 \%$ of $50 \mathrm{~mm} \mathrm{Hg}$. The gas exchange performance was characterized for each device by measuring the carbon dioxide exchange at randomly varied beat rates of $0,30,60,120,180,240$, and 300 beats $/ \mathrm{min}$, with 2 sets of data at each beat rate. In 5 of the 7 calf experiments, the device was repositioned after characterization in the right atrium location such that it was entirely within the IVC, spanning the renal veins. Characterization was repeated in the IVC location for comparison with the results in the right atrium position.

Minute ventilation was reduced in some animals to stress the ability of the device to remove carbon dioxide under hypercapnic conditions, with a concomitant venous $\mathrm{PCO}_{2}$ increase. The carbon dioxide gas exchange rate was calculated by multiplying the sweep gas flow rate by the carbon dioxide gas fraction exiting the device. The carbon dioxide exchange rate depends on the venous blood $\mathrm{PCO}_{2}$ in contact with the fiber bundle, which can differ among experiments and animals, even with appropriate ventilatory adjustments. For a more direct comparison between devices, we normalized the carbon dioxide exchange rate to a venous $\mathrm{PCO}_{2}$ of $50 \mathrm{~mm}$ $\mathrm{Hg}$. This normalized carbon dioxide exchange rate was determined by multiplying the carbon dioxide exchange by $50 \mathrm{~mm} \mathrm{Hg}$ divided by the measured $\mathrm{PcO}_{2}$.

Oxygen exchange was not used to characterize the device performance because of the difficulty in obtaining accurate measurements in vivo. Calculation of oxygen exchange on the blood side would require the ability to accurately measure blood flow past the portion of the device in the SVC and concurrently to the portion in the IVC, and if these measurements could in fact be made, they would not reflect the changes in flow rate caused by the various venous pathways converging along the vena cava. On the gas side, accurate measurement of oxygen exchange is limited by the small difference in mass flow rate and oxygen fraction entering and exiting the fiber bundle. The standard error of the oxygen exchange calculation from gas flow measurements would be greater than the difference in oxygen exchange rate between devices.

After completion of the acute trials, the animal was deeply anesthetized and killed with a bolus of potassium chloride, followed by complete autopsies. All animal procedures were conducted under supervision of a staff surgical veterinarian and were in accordance with National Institutes of Health and University of Pittsburgh guidelines for the care and use of experimental animals in research.

\section{Chronic In Vivo Characterization}

For the chronic in vivo trials, $\mathrm{HC}$ devices with $13-\mathrm{mL}$ balloons were inserted into the IVC position and characterized according to the same procedure used for the acute experiments. The IVC position was chosen because once animals were awake and standing in their stalls, the IVC was the only anatomic location where the devices remained straight in coniguration without concerns over kinking. After characterization, the calf was revived and transferred to a postoperative critical and long-term animal care room. All catheters remained in the calf for long-term monitoring

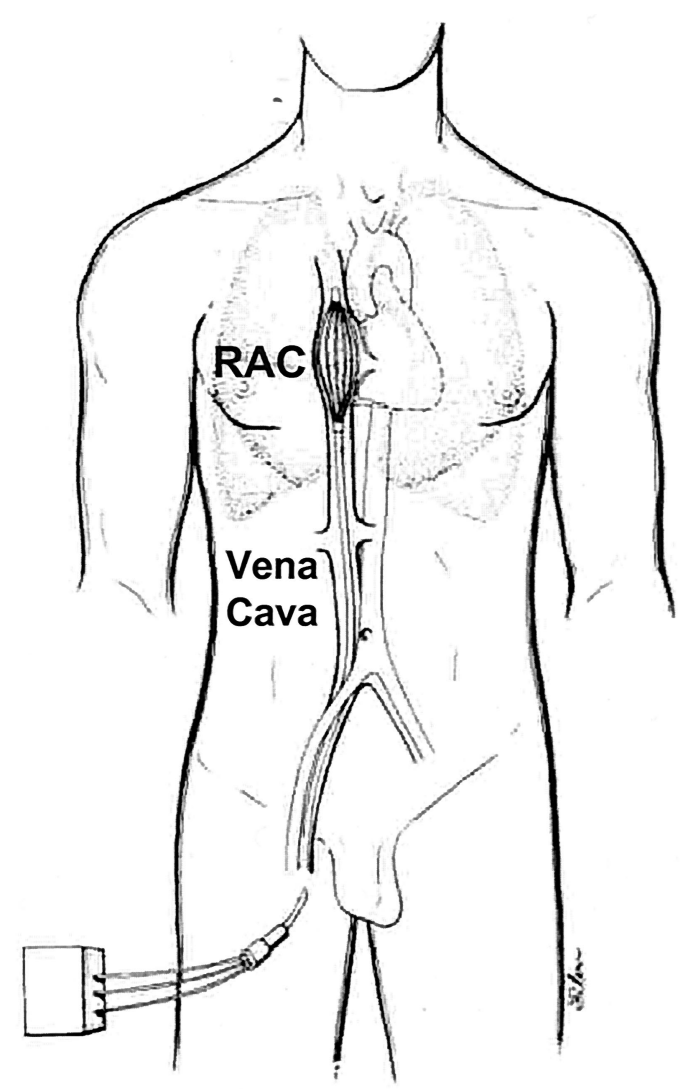

Figure 2. A schematic of the respiratory assist catheter (RAC). The exit manifold is positioned outside the body, where the 3 ports can be accessed for oxygen $(100 \%)$ delivery, vacuum, and a helium port connected to an external console that drives pulsation of the balloon up to 300 beats/min. The hollow fiber bundle attached to the end of the gas delivery catheter is 30 to $40 \mathrm{~cm}$ long and can very in surface area from 0.17 to $0.43 \mathrm{~m}^{2}$.

of pressures, blood gases, hematocrit levels, blood chemistry, and cardiac output. Heparin was continuously administered through the femoral vein line so that activated clotting times remained between 400 and 500 seconds for the first day and between 200 and 300 seconds thereafter. Units of blood were administered as needed on the basis of hematocrit levels. Balloon pulsation was maintained at 120 beats/min continuously with a Datascope intra-aortic balloon console (because of its autofilling capability). Sweep gas flow rate and fraction of carbon dioxide in the gas exiting the fibers were continuously recorded in a computer for calculation of carbon dioxide exchange. Gas exchange, hemodynamics, and hematologic evaluation were carried out for a 4-day period. After completion, the animal was anesthetized and killed in the same manner as for the acute trials. Full autopsies were carried out immediately after trial termination.

\section{Results}

In Vitro

The average in vitro oxygen and carbon dioxide exchange results in water for devices having a 13-, 25-, and 40-mL 

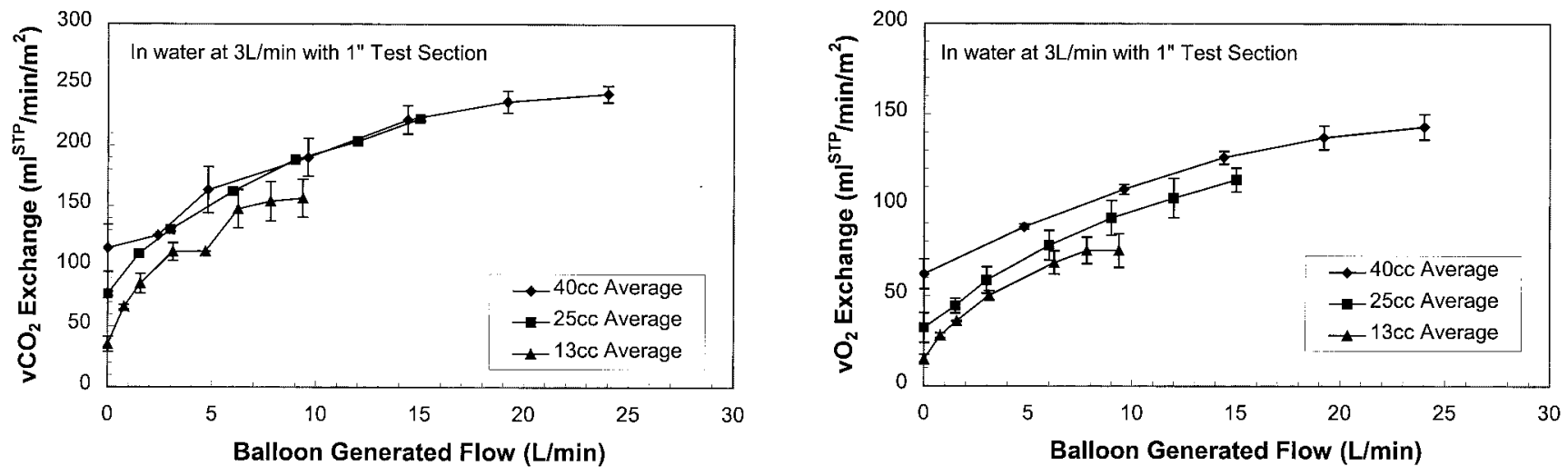

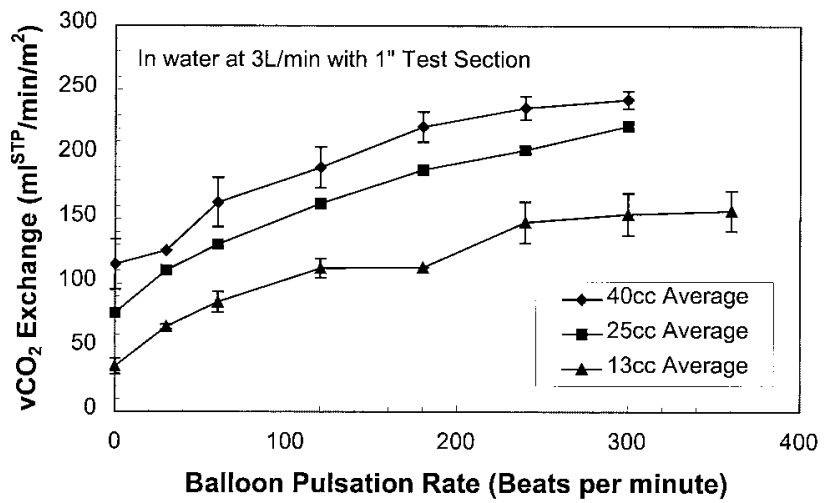

Figure 3. Average carbon dioxide exchange in water with a 1-inch test section. Numbers are an average of 6 to 8 determinations for each designated point. The diameter of the mock vena cava test section was 1 inch $(25 \mathrm{~mm})$.

balloon, respectively, are shown in Figures 3 and 4. The gas exchange results are shown both as a function of the balloon pulsation rate and the balloon-generated flow rate, which is determined from twice the pulsation rate (blood is moved both in inflation and deflation) multiplied by the balloon volume. The maximum pulsation rate at which a given balloon volume can be fully inflated and deflated is governed by the pressure and vacuum pump capacities of the drive system, as well as by the helium flow pathway characteristics leading to the balloon. When this maximum pulsation rate is exceeded and the balloon is no longer able to fully inflate or deflate, the gas exchange begins to plateau, as shown in the bottom graphs of Figures 3 and 4 . From the bottom graphs, it can be seen that the larger the balloon, the better the maximum achievable gas exchange. However, to separate the limitations of the balloon drive system from inherent differences in gas exchange between devices with different balloon sizes, the gas exchange is also shown as a function of the balloon-generated flow (ie, the amount of fluid per minute pumped in and out of the fiber bundle by the balloon). From these results (upper graphs of Figures 3

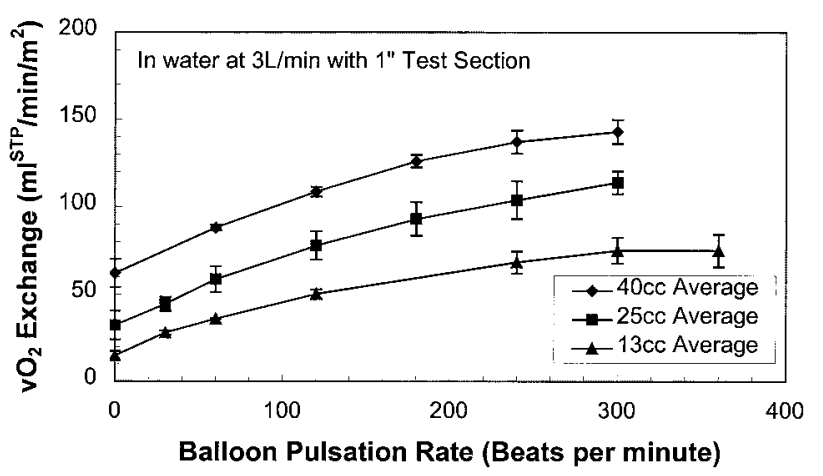

Figure 4. Average oxygen exchange in water with a 1-inch test section. Numbers are an average of 6 to 8 determinations for each designated point.

and 4), it was found that the larger balloon devices still outperformed the smallest balloon device for a given balloon-generated flow rate. The maximum achieved gas exchange rate in a $25-\mathrm{mm}$ test section with water flowing at 3 $\mathrm{L} / \mathrm{min}$ was $240 \mathrm{~mL} \mathrm{STP} \cdot \mathrm{min}^{-1} \cdot \mathrm{m}^{-2}$ for carbon dioxide and $140 \mathrm{~mL}^{\mathrm{STP}} \cdot \min ^{-1} \cdot \mathrm{m}^{-2}$ for oxygen, which occurred with the largest balloon device at a balloon-generated flow of approximately $24 \mathrm{~L} / \mathrm{min}$.

The gas exchange results in a $25-\mathrm{mm}$ test section also showed that a larger balloon device performed substantially better than a smaller balloon device when the balloon was in a static, nonpulsing, deflated mode. These results suggest that the size of the bundle diameter, which is determined by the balloon size, is the factor that leads to improved gas exchange performance (Table 1). The 25-mL and 13-mL devices were tested in a $19-\mathrm{mm}$ test section at the same flow rate to further evaluate this result (the 40-mL devices would not easily fit in this size test section). Figure 5 shows the carbon dioxide exchange results in the 19-mm section test versus those in the $25-\mathrm{mm}$ test section. For both devices, the gas exchange was $25 \%$ higher $(P<.05)$ in the smaller test section, and the larger balloon device outperformed the smaller device both at maximum pulsation rate and in the 
TABLE 1. Comparison of average pressure decrease across devices of different balloon sizes and at different pulsation rates. The effective outer diameter of the fiber bundles for each size balloon device is also shown. Tube diameters are expressed in inches and millimeters

\begin{tabular}{|c|c|c|c|c|c|}
\hline \multirow[b]{2}{*}{$\begin{array}{l}\text { Balloon } \\
\text { volume }\end{array}$} & \multirow[b]{2}{*}{$\begin{array}{l}\text { Inflated outer } \\
\text { diameter }\end{array}$} & \multicolumn{2}{|c|}{ 3/4-inch Tube $(19 \mathrm{~mm})$} & \multicolumn{2}{|c|}{ 1-inch Tube $(25 \mathrm{~mm})$} \\
\hline & & BPM & $\begin{array}{c}\text { Mean pressure decrease } \\
(\mathrm{mm} \mathrm{Hg})\end{array}$ & BPM & $\begin{array}{c}\text { Mean pressure decrease } \\
(\mathrm{mm} \mathrm{Hg})\end{array}$ \\
\hline \multirow[t]{3}{*}{$13 \mathrm{~mL}$} & $15 \mathrm{~mm}$ & 0 & $2.4 \% \pm 4.6 \%$ & 0 & $0.8 \% \pm 8.4 \%$ \\
\hline & & 180 & $5.2 \% \pm 1.3 \%$ & 180 & $1.0 \% \pm 0.0 \%$ \\
\hline & & 300 & $4.5 \% \pm 2.2 \%$ & 300 & $1.2 \% \pm 4.0 \%$ \\
\hline \multirow[t]{3}{*}{$25 \mathrm{~mL}$} & $17 \mathrm{~mm}$ & 0 & $7.7 \% \pm 0.3 \%$ & 0 & $2.4 \% \pm 2.9 \%$ \\
\hline & & 180 & $27.1 \% \pm 5.5 \%$ & 180 & $2.8 \% \pm 2.8 \%$ \\
\hline & & 300 & $28.6 \% \pm 7.0 \%$ & 300 & $3.4 \% \pm 0.6 \%$ \\
\hline \multirow[t]{3}{*}{$40 \mathrm{~mL}$} & $19 \mathrm{~mm}$ & - & - & 0 & $0.9 \% \pm 1.1 \%$ \\
\hline & & - & - & 180 & $3.1 \% \pm 0.7 \%$ \\
\hline & & - & - & 300 & $3.3 \% \pm 0.9 \%$ \\
\hline
\end{tabular}

static balloon-deflated mode. In the $19-\mathrm{mm}$ test section, the maximum carbon dioxide exchange of the $25-\mathrm{mL}$ balloon device was $255 \mathrm{~mL}^{\mathrm{STP}} \cdot \mathrm{min}^{-1} \cdot \mathrm{m}^{-2}$, whereas in a $25-\mathrm{mm}$ test section it was $205 \mathrm{~mL}^{\mathrm{STP}} \cdot \mathrm{min}^{-1} \cdot \mathrm{m}^{-2}$.

The improved exchange, however, was at the expense of a pressure decrease across the device. Table 1 shows the decrease in pressure measurements at $3 \mathrm{~L} / \mathrm{min}$ water flow for each device in the 2 test sections. In the $25-\mathrm{mm}$ test section the maximum pressure decrease for the largest balloon device at maximum pulsation rate was $3.3 \mathrm{~mm} \mathrm{Hg}$. However, in the $19-\mathrm{mm}$ test section the average pressure decrease across the length of the $25-\mathrm{mL}$ balloon device was $29 \mathrm{~mm} \mathrm{Hg}$, and for the 13-mL balloon device, it was $4.5 \mathrm{~mm}$ $\mathrm{Hg}$ at a pulsation rate of 300 beats/min.

\section{Acute In Vivo}

Seven acute in vivo calf tests were conducted in which 2 and, when possible, 3 devices, each having a different balloon size, were tested in the right atrium and in the IVC of each animal. Figure 6 is representative of the carbon dioxide exchange results generated during each of the 7 acute tests. All devices tested generated greater gas exchange in the right atrium region compared with that in the IVC region. In each test, as reflected in Figure 6, one device clearly removed more carbon dioxide than the others. Figure 7 shows the carbon dioxide exchange results in the right atrium position for each test, with the average performance of all tests per balloon size shown on the far right. As shown in Figure 7, the results were inconsistent in different calves as to which balloon size device performed better. Correlating these findings with postmortem determinations of the size of the vena cava and the right atrium is difficult because of the rapid change in compliance of these structures after death. Nevertheless, we interpret these findings as most consistent with gas exchange, as determined by the relationship of the device size to that of its containing chamber. This interpretation is consistent with our in vitro experi- ments measuring gas exchange of various size devices in 19- and 25-mm test sections (Figure 5).

Hemodynamically, and particularly for $40-\mathrm{mL}$ balloon devices, the cardiac output was significantly affected by insertion of the device into the right atrium, as shown in Table 2. Smaller devices had no statistically significant effect on cardiac output. These findings are most consistent with the important relationship that exists between the size of the device, the vascular anatomy of the recipient, and venous return.

The average carbon dioxide exchange for all devices of a given balloon size in the right atrium position compared with that seen in the IVC position is shown in Figure 8. For each location, there was no statistical difference between balloon sizes, but there was a significant difference in carbon dioxide exchange between locations $(P=.05$, right atrium vs IVC). In the right atrium position the average carbon dioxide exchange was approximately $305 \mathrm{~mL}^{\text {STP }}$. $\min ^{-1} \cdot \mathrm{m}^{-2}$, and in the IVC position it was approximately $265 \mathrm{~mL}^{\mathrm{STP}} \cdot \min ^{-1} \cdot \mathrm{m}^{-2}$.

\section{Chronic In Vivo}

The carbon dioxide exchange rate of a $13-\mathrm{mL}$ balloon device in the IVC position was recorded during 2 chronic in vivo trials lasting 4 days each. Although devices spanning the right atrium show better gas exchange (Figure 6), the IVC position was necessary to maintain the device in a straight conıguration without concerns over kinking once the calf awakened and stood up. These gas exchange values were recorded with the animal awake and with the balloon pulsing at 120 beats/min. For both trials, the carbon dioxide exchange rate was found to be consistently within a range of 220 to $280 \mathrm{~mL}^{\mathrm{STP}} \cdot \mathrm{min}^{-1} \cdot \mathrm{m}^{-2}$, with little to no gas exchange degradation over the 4-day period. These results reflect gas exchange at a suboptimal beat rate necessitated by the need to use a Datascope console because of its autofilling capability. 


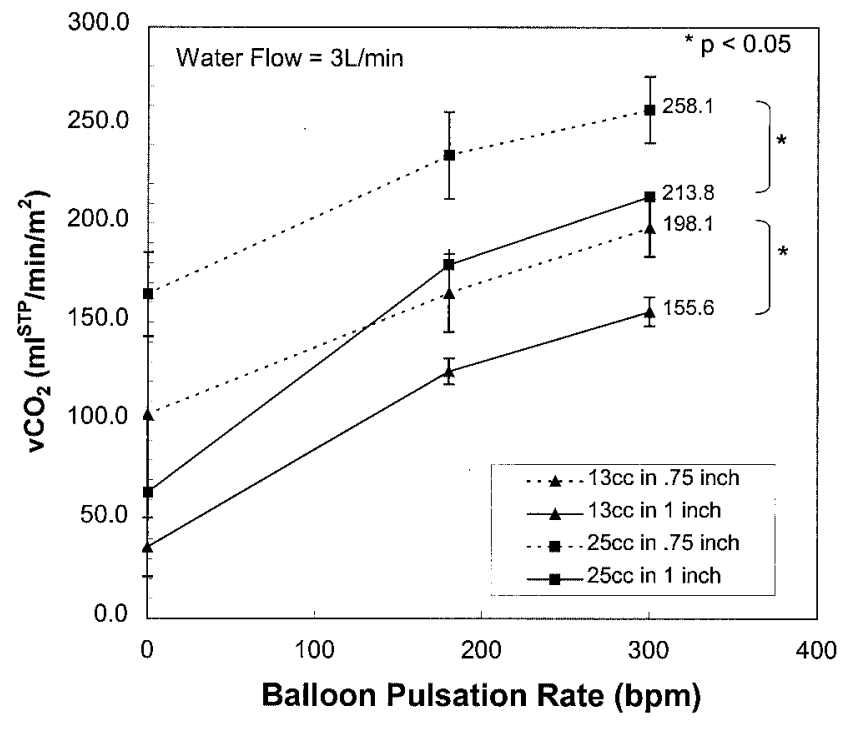

Figure 5. Comparison of carbon dioxide exchange of a $13-\mathrm{mL}$ and $25-\mathrm{mL}$ balloon device in a 1-inch $(25 \mathrm{~mm})$ test section versus a 3/4-inch (19 $\mathrm{mm})$ test section.

For both chronic trials, the initial samples for plasmafree hemoglobin were taken after the jugular vein had been exposed for insertion but before the device had actually been inserted. In the first trial the plasma-free hemoglobin levels began at $6 \mathrm{mg} / \mathrm{dL}$ (before insertion) and increased to $12 \mathrm{mg} / \mathrm{dL}$ during the first 24 hours, then gradually decreased over the course of the trial to a final level of $5 \mathrm{mg} / \mathrm{dL}$. In the second trial the level of plasma-free hemoglobin began at 9 $\mathrm{mg} / \mathrm{dL}$ and from that point gradually declined over the 4-day trial to a final level of $4 \mathrm{mg} / \mathrm{dL}$.

Changes in the carbon dioxide exchange rate during permissive hypercapnea are shown in Table 3. An increase in the carbon dioxide exchange was observed from a baseline venous $\mathrm{PCO}_{2}$ of $49 \mathrm{~mm} \mathrm{Hg}$ to an increased $\mathrm{PCO}_{2}$ of 67 $\mathrm{mm} \mathrm{Hg}$ during implantation of the $\mathrm{HC}$ in a calf. The carbon dioxide exchange rate is shown as the fractional increase relative to that of the baseline $\mathrm{PCO}_{2}$. The device increased its carbon dioxide exchange rate by $48 \%$ in response to the permissive hypercapnea, an increase somewhat greater than the percentage increase in $\mathrm{PCO}_{2}$ associated with the hypercapnea.

Autopsies of these animals were unremarkable, with no distal emboli. A small amount of fibrin deposition at the distal and proximal manifolds of the device was observed.

\section{Discussion}

Recent reports have indicated that acute respiratory failure in the United States has an incidence of greater than 300,000 cases per year. In the adult population the mortality ranges from $11 \%$ to $60 \%$, depending on the age group studied. ${ }^{29}$ The need for improved care in this patient population has
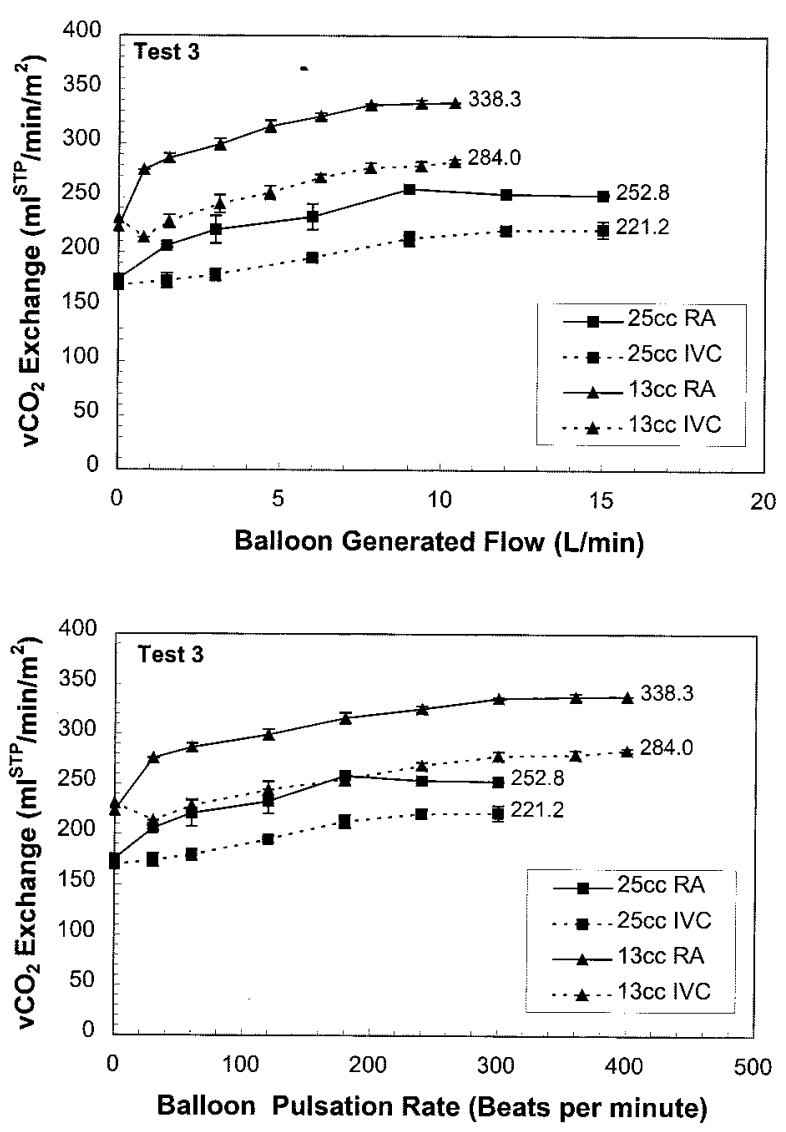

Figure 6. Example of short-term in vivo test results from test 3.

formed the basis for a continuing interest in the development of better ventilator strategies, new drug therapies, and artificial lung devices, including improved approaches to extracorporeal membrane oxygenation in the treatment of acute lung failure and in the management of patients on ventilators.

In this context our efforts have concentrated on the development of a respiratory assist catheter that will allow reductions in ventilator support by providing up to $50 \%$ of the gas exchange requirements $(125 \mathrm{~mL} / \mathrm{min}$ oxygen and carbon dioxide) in ventilator patients with reversible acute respiratory failure. This level of respiratory support can be calculated to have a beneficial effect in adult patients with only $30 \%$ of their lung functional (Figure 1). Because the device is not intended for total support, it depends on the fact that damage to the lungs in patients with ARDS is not uniform and that numerous areas of normal lung can be demonstrated throughout severely diseased segments. ${ }^{30}$ The ability to lower tidal volumes and to more gently ventilate these normally compliant lung segments appears to have survival value in the patient with ARDS and is instrumental in the conceptual approach to eventually implementing a respiratory assist catheter in a clinical setting. ${ }^{5}$ 


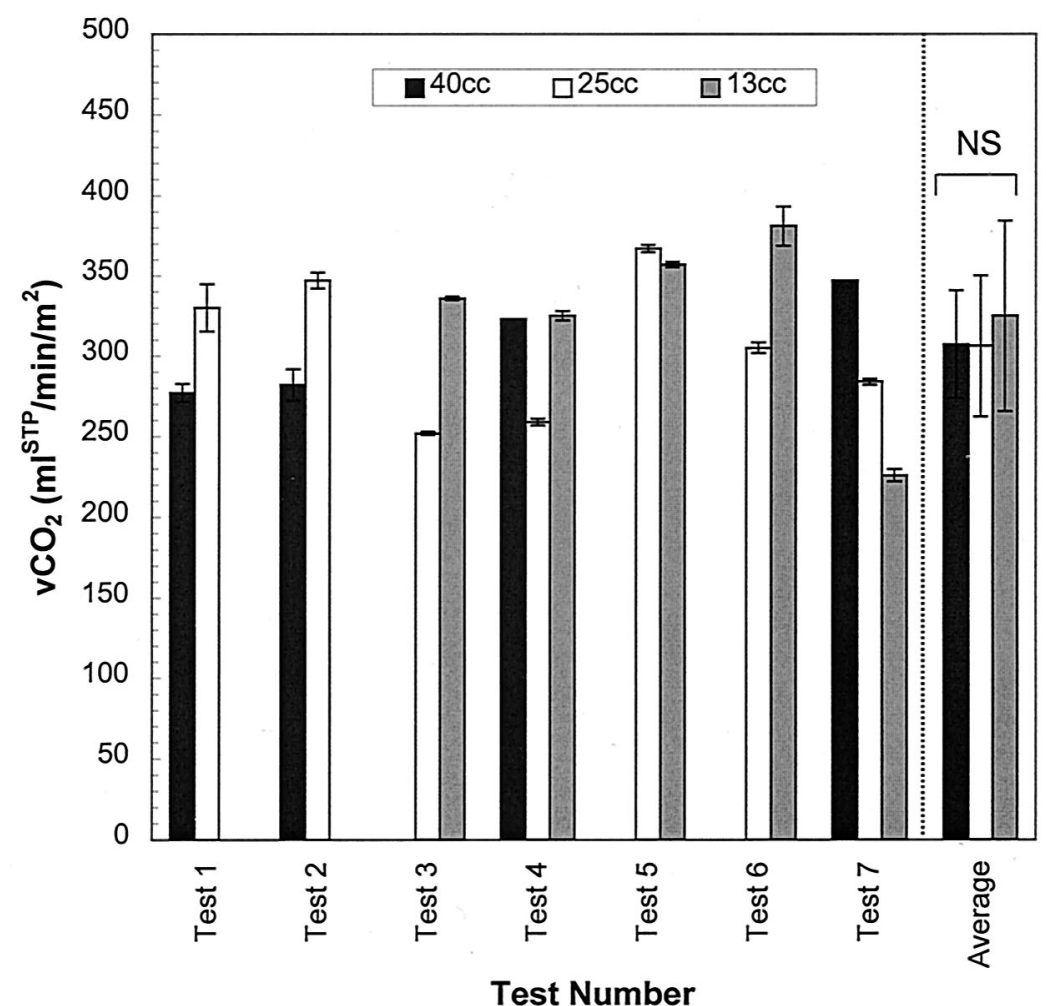

Figure 7. Summary of acute in vivo test results in 7 calves. Average carbon dioxide exchange for each balloon size over all tests is shown to the right. There was no statistical difference in average exchange on the basis of balloon size.

TABLE 2. Summary of cardiac output measurements made during acute invivo trials before and after device insertion, while device was in the right atrium position

\begin{tabular}{|c|c|c|c|c|c|c|c|c|c|c|c|c|c|c|}
\hline \multirow{4}{*}{$\begin{array}{l}\text { Animal } \\
\text { size (kg) } \\
\text { Insertion }\end{array}$} & \multicolumn{14}{|c|}{ Cardiac output in the right atrium (L/min) } \\
\hline & \multicolumn{2}{|c|}{ Test 1} & \multicolumn{2}{|c|}{ Test 2} & \multicolumn{2}{|c|}{ Test 3} & \multicolumn{2}{|c|}{ Test 4} & \multicolumn{2}{|c|}{ Test 5} & \multicolumn{2}{|c|}{ Test 6} & \multicolumn{2}{|c|}{ Test 7} \\
\hline & \multicolumn{2}{|c|}{110} & \multicolumn{2}{|c|}{92} & \multicolumn{2}{|c|}{103} & \multicolumn{2}{|c|}{79} & \multicolumn{2}{|c|}{90} & \multicolumn{2}{|c|}{92} & \multicolumn{2}{|c|}{91} \\
\hline & Pre & Post & Pre & Post & Pre & Post & Pre & Post & Pre & Post & Pre & Post & Pre & Post \\
\hline $40 \mathrm{~mL}$ & 10.9 & 5.1 & 8.1 & 8.3 & - & - & 8.7 & 7.0 & - & - & - & - & 10.1 & 6.1 \\
\hline $25 \mathrm{~mL}$ & 13.2 & 12.3 & 9.2 & 10.2 & 13.5 & 12.6 & 9.3 & 9.3 & 7.6 & 6.7 & 8.8 & 7.2 & - & 9.8 \\
\hline $13 \mathrm{~mL}$ & - & - & - & - & 13.5 & 14.3 & 9.7 & 8.6 & 7.6 & 8.5 & 8.8 & 8.1 & 9.6 & 8.8 \\
\hline
\end{tabular}

Testing was carried out in 7 calves.

A key element of the respiratory assist catheter under development is a central pulsating balloon that significantly enhances gas exchange in the venous system. The goal of the present experiments was to characterize the gas exchange and hemodynamic effects of the respiratory assist catheter as a function of balloon size in large animals with weights equivalent to those of human subjects. In the controlled in vitro environment of the mock venous circulatory system, the results clearly demonstrated that a device with a larger balloon provided higher gas exchange rates, both for carbon dioxide and oxygen (Figures 3-5). The larger balloon devices not only could be driven to generate a larger balloon flow but, for a given balloon-generated flow rate, yielded a larger gas exchange rate. A larger balloon inherently pulses with a greater stroke volume, which penetrates more effectively across the fiber bundle than a smaller balloon.

Device size as a function of the diameter of the mock vena cava was also examined in the in vitro circulatory system. Gas exchange for a device uniformly improved as 


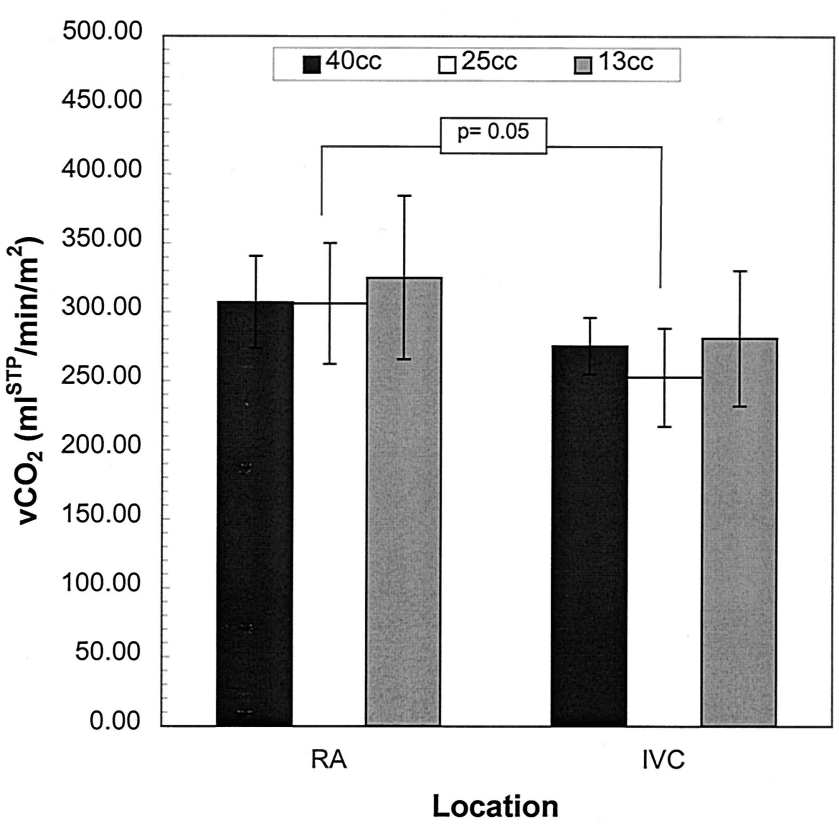

Figure 8. Acute in vivo average maximum carbon dioxide exchange I the right atrium and IVC positions in 7 calves.

TABLE 3. Effect of permissive hypercapnea on carbon dioxide exchange during acute implantation in the calf

\begin{tabular}{|c|c|c|}
\hline $\begin{array}{l}\text { Venous } \mathrm{PcO}_{2} \\
(\mathrm{~mm} \mathrm{Hg})\end{array}$ & $\begin{array}{l}\mathrm{VCO}_{2} \text { normalized to } \mathrm{VCO}_{2} \text { at } \\
\text { venous } \mathrm{PCO}_{2} \text { of } 49.1 \mathrm{~mm} \mathrm{Hg}\end{array}$ & $\mathrm{Pco}_{2} / 49.1 \mathrm{~mm} \mathrm{Hg}$ \\
\hline 49.1 (baseline) & 1 & 1 \\
\hline 54.3 & 1.13 & 1.11 \\
\hline 60.2 & 1.33 & 1.23 \\
\hline 63.3 & 1.44 & 1.29 \\
\hline 66.9 & 1.48 & 1.36 \\
\hline
\end{tabular}

$\mathrm{VCO}_{2}$, Carbon dioxide consumption.

the diameter of the test section was reduced (Figure 5). Similar findings have also been reported by von Segesser and associates ${ }^{31}$ and reflect the increased longitudinal fluid velocities in smaller vessels, which can more effectively penetrate the fiber bundle. A point is reached, however, with smaller diameter conduits at which the pressure decrease across the device becomes excessive (Table 1), and any extrapolation to an in vivo setting would not be hemodynamically tolerated.

With in vitro testing, the fluid is mechanically circulated at a fixed rate past the respiratory assist catheter, regardless of pressure decreases engendered by resistance to flow. These issues, however, become paramount when testing in vivo, where, in contrast to in vitro results, the acute in vivo results were much less consistent between balloon sizes. These findings are best interpreted as reflecting the important relationship that exists between the size of the device and the central venous anatomy of the recipient. The largest $40-\mathrm{mL}$ balloon devices in the position spanning the right atrium resulted in a significant reduction in cardiac output in 3 of the 4 trials in which the larger device was tested. In no case did a device with a $25-\mathrm{mL}$ or $13-\mathrm{mL}$ balloon cause such a result in $90-$ to $100-\mathrm{kg}$ calves. For each individual test, one device would clearly outperform the other, as typified by Figure 7 . There was no difference, however, in gas exchange performance when averaged over all trials (Figure 7). Therefore, smaller balloon devices that can generate comparable balloon flow $(2 \times$ balloon size $\times$ beat rate) at faster beat rates would appear to have significant advantage in terms of safety, ease of insertion, and hemodynamic stability of the recipient.

The in vivo carbon dioxide exchange levels were, on average, $305 \mathrm{~mL} \cdot \min ^{-1} \cdot \mathrm{m}^{-2}$. Thus with an anticipated device membrane surface area of $0.4 \mathrm{~m}^{2}$, for an average adult male patient, a carbon dioxide exchange rate of 125 $\mathrm{mL} / \mathrm{min}$, or approximately $50 \%$ of basal carbon dioxide production, is expected if the device performance scales linearly with surface area. Devices with membrane surface areas of $0.5 \mathrm{~m}^{2}$ were tested in human subjects in the early 1990s by Mortenson and colleagues ${ }^{24}$ without hemodynamic concerns. Although oxygen exchange could not be accurately measured in vivo, an estimation of in vivo oxygen exchange can be projected from our in vitro results. Vaslef and coworkers ${ }^{26}$ have demonstrated that the oxygen exchange rate of membrane oxygenators tested in blood consistently correlated with exchange rates in water by a factor of 2 to 3 . Our own studies comparing the performance of the $\mathrm{HC}$ device in an in vitro circuit filled with water versus with blood demonstrated a similar correlation factor. ${ }^{27}$ The in vitro water results for the 3 balloon sizes demonstrated maximum exchange rates of $140 \mathrm{~mL} \cdot \mathrm{min}^{-1}$ $\cdot \mathrm{m}^{-2}$, which, for a device of $0.4 \mathrm{~m}^{2}$, corresponds to an oxygen exchange rate of $56 \mathrm{~mL} / \mathrm{min}$. Using the water-toblood correlation factor of 2 to 3 , an in vivo oxygen exchange rate of 110 to $170 \mathrm{~mm} / \mathrm{min}$ is predicted, which is approximately $50 \%$ of basal metabolic oxygen consumption.

Devices positioned so as to span the right atrium demonstrated significantly better gas exchange when compared with devices positioned entirely in the IVC (Figure 8). Under these latter conditions, blood entering the right atrium from the upper body would not be exposed to the gas exchange fibers, creating a significant shunt fraction with reduced overall gas exchange.

While awaiting longer animal-testing capabilities, devices were chronically tested in vivo for 4 days with sustained gas exchange in calves and normal functioning devices at the time of animal death. Although the goal for the respiratory assist catheter is 7 to 10 days of pulmonary support, shorter intervals might be of benefit. The recent 
National Institutes of Health trial has provided evidence that as early as 48 hours after the institution of a lung-protective strategy, an improvement in the pulmonary status of patients with ARDS can be seen. ${ }^{5}$ Jayroe and associates ${ }^{32}$ have confirmed these clinical findings in an ovine smoke inhalation model of acute lung injury. Importantly, and as part of this therapy with reductions in tidal volume and minute ventilation, hypercapnea is inevitable. The ability of the respiratory assist catheter to increase its carbon dioxide output with permissive hypercapnea (Table 3 ) would predict its ability to respond to tidal volume reduction in the therapy of acute respiratory failure.

In summary and as part of a continuing evaluation of gas exchange in the venous system, ${ }^{4,11-28}$ the present work supports the concept that a respiratory assist catheter can be made both hemodynamically compatible and gas exchange efficient while providing $50 \%$ of the basal gas exchange requirements in human subjects. Whether this level of gas exchange will prove beneficial in a patient setting will be determined in clinical trials.

\section{References}

1. Ashbaugh DG, Bigelow DB, Petty TL, Levine BE. Acute respiratory distress in adults. Lancet. 1967;2:319-23.

2. Zilberberg MD, Epstein SK. Acute lung injury in the medical ICU: comorbid conditions, age, etiology, and hospital outcome. Am J Respir Crit Care Med. 1998;157:1159-64.

3. Bartlett RH, Roloff DW, Custer JR, Younger JG, Hirschi RB. Extracorporeal life support: the University of Michigan Experience. JAMA. 2000;283:904-8.

4. Hattler BG, Federspiel WJ. Gas exchange in the venous system: support for the failing lung. In: Vasleff SN, Anderson RW, editors. The artificial lung. New York: Viking Press. In press.

5. The Acute Respiratory Distress Syndrome Network. Ventilation with lower tidal volumes as compared with traditional tidal volumes for acute lung injury and the acute respiratory distress syndrome. $N$ Engl J Med. 2000;342:1301-8.

6. Hirschl RB, Pranikoff T, Wise C, et al. Initial experience with partial liquid ventilation in adult patients with the acute respiratory distress syndrome. JAMA. 1996;275:383-9.

7. Fort P, Farmer C, Westerman J, et al. High-frequency oscillatory ventilation for adult respiratory distress syndrome-a pilot study. Crit Care Med. 1997;25:937-47.

8. Anzueto A, Baughman RP, Guntupalli KK, et al. Aerosolized surfactant in adults with sepsis-induced acute respiratory distress syndrome. Exosurf Acute Respiratory Distress Syndrome Sepsis Study Group. N Engl J Med. 1996;334:1417-21.

9. Dellinger RP, Zimmerman JL, Taylor RW, et al. ffects of inhaled nitric oxide in patients with acute respiratory distress syndrome: results of a randomized phase II trial. Inhaled Nitric Oxide in ARDS Study Group. Crit Care Med. 1998;26:15-23.

10. The ARDS Network. Ketoconazole for early treatment of acute lung injury and acute respiratory distress syndrome: a randomized controlled trial. JAMA. 2000;283:1995-2002.

11. Federspiel W, Sawzik P, Borovetz H, Reeder GD, Hattler BG. Temporary support of the lungs: the artificial lung. In: Cooper DKC, Miller LW, Patterson GA, editors. Transplantation and replacement of thoracic organs. 2nd ed. Dordrecht, The Netherlands: Kluwer Academic Pubishers; 1996. p. 717-28.

12. Hattler BG, Reeder GD, Sawzik PJ, et al. Development of an intravenous membrane oxygenator: enhanced intravenous gas exchange through convective mixing of blood around hollow fiber membranes. Artif Organs. 1994;18:806-12.
13. Hattler BG, Reeder GD, Sawzik PJ, et al. Development of an intravenous membrane oxygenator: a new concept in mechanical support for the failing lung. J Heart Lung Transplant. 1994;13:1003-8.

14. Macha M, Federspiel WJ, Lund LW, et al. Acute in vivo studies of the Pittsburgh intravenous membrane oxygenator. ASAIO J. 1996;42: M609-15.

15. Lund LW, Hattler BG, Federspiel WJ. Is condensation the cause of plasma lekage in microporous hollow fiber membrane oxygenators? $J$ Membr Sci. 1998;147:87-93.

16. Hout MS, Hattler BG, Federspiel WJ. Validation of a model for flow-dependent carbon dioxide exchange in artificial lungs. Artif Organs. 2000;24:114-8.

17. Federspiel WJ, Williams JL, Hattler BG. Gas flow dynamics in hollow fiber membranes. Am Inst Chem Eng J. 1996;42:2094-9.

18. Hewitt TJ, Hattler BG, Federspiel WJ. A mathematical model of gas exchange in an intravenous membrane oxygenator. Ann Biomed Eng. 1998;26:166-78.

19. Federspiel WJ, Hewitt TJ, Hattler BG. Experimental evaluation of a model for oxygen exchange in a pulsating intravascular artificial lung. Ann Biomed Eng. 2000;28:160-7.

20. Federspiel WJ, Hout MS, Hewitt TJ, et al. Development of a low flow resistance intravenous oxygenator. ASAIO J. 1997;43:M725-30.

21. Federspiel WJ, Golob JF, Merrill TL, et al. Ex-vivo testing of the intravenous membrane oxygenator (IMO). ASAIO J. 2000;46:261-7.

22. Mortensen JD. An intravenacaval blood gas exchange (IVCBGE) device, a preliminary report. Trans ASAIO. 1987;33:570-3.

23. Mortensen JD. Intravascular oxygenator: a new alternative method for augmenting blood gas transfer in patients with acute respiratory failure. Artif Organs. 1992;16:75-82.

24. Conrad SA, Bagley A, Bagley B, et al. Major findings from the clinical trials of the intravascular oxygenator. Artif Organs. 1994;18: 846-63.

25. Hattler BG, Johnson PC, Sawzik PJ, Schapp RN. Respiratory dialysis: a new concept in pulmonary support. ASAIO J. 1992;38:M322-5.

26. Vaslef SN, Mockros LF, Anderson RW, Leonard RJ. Use of a mathematical model to predict oxygen transfer rates in hollow fiber membrane oxygenators. ASAIO J. 1994;40:990-6.

27. Federspiel WJ, Hewitt T, Hout MS, et al. Recent progress in engineering the Pittsburgh intravenous membrane oxygenator. ASAIO J. 1996;42:M435-42.

28. Federspiel WJ, Hattler BG. Sweep gas flowrate and $\mathrm{CO}_{2}$ exchange in artificial lungs. Artif Organs. 1996;20:1050-6.

29. Behrendt CE. Acute respiratory failure in the United States. Incidence and 31-day survival. Chest. 2000;118:1100-5.

30. Ware LB, Matthay MA. The acute respiratory distress syndrome. N Engl J Med. 2000;342:1334-49.

31. von Segesser LK, Tonz M, Mihaljevic T, Marty B, Leskosek B, Turina $\mathrm{M}$. Influence of host vessel diameter on oxygen transfer. ASAIO J. 1996;42:246-9.

32. Jayroe JB, Alpard SK, Donfang W, Deyo DJ, Murphy JA, Zwischenberger JB. Hemodynamic stability during arteriovenous carbondioxide removal for adult respiratory distress syndrome: a prospective randomized outcomes study in adult sheep. ASAIO J. 2001;47:211-4.

\section{Discussion}

Dr Diedrich E. Birnbaum (Regensburg, Germany). I think it is still a fascinating device. However, the clinical situation is quite different from what we learned from the cows in gas exchange. In the clinical setup, normally the condition of the patients is septic and they are in chronic pulmonary failure. Therefore, to deliver oxygen is one side in this situation, and acidosis is the other side. Therefore, the gas exchange is only one part, which certainly can be fulfilled by these devices. However, coagulation-anticoagulation situations in these patients and results on acidotic situations of these patients are very important, and I wonder how this will be evaluated enough in experimental setups to go on to the clinical situation. 
Dr Hattler. Acidosis in these patients with respiratory failure is largely respiratory, and the device will remove carbon dioxide very nicely. We did not show the $\mathrm{pH}$ values in these cows, but they were maintained at normal levels. The devices are coated with a heparin molecule that actually reduces the need for anticoagulation, although it does not eliminate it. Activated clotting times run in the range of 150 to 180 seconds. Therefore, you can use this device with minimal anticoagulation in the cow. Whether this will be true in human subjects, we do not know yet. 